\title{
The Significance of Livelihood Support Projects to Health Communication Strategies in Resource-deprived Settings: A Look at the Medical Male Circumcision Programme in Siaya County, Kenya
}

\author{
Osir Otteng $^{1 *} \quad$ Michael Kiptoo $^{2} \quad$ Peres Wenje ${ }^{3}$, \\ 1.South Eastern Kenya University, Technology, P.O. Box 170 -90200, Kitui, Kenya \\ 2.Kenya Medical Training College, Off Ngong Road, P.O. BOX 30195-00100, Nairobi, Kenya \\ 3. Masinde Muliro University of Science and Technology, P.O. Box 190-50100, Kakamega, Kenya
}

\begin{abstract}
Behaviour change communicators and health experts often assume that individual beliefs and perceptions hold the key to explaining health behaviours, thereby ignoring the extraneous constraints that obtain in the individual's environment. Access to basic resources, such as food clothing and shelter, can be central to developing an understanding for health transactions, particularly in severely resource-deprived populations found in rural and informal urban dwellings, where basic survival at times overrides all other considerations. In such situations, specific livelihood improvement programmes targeting the intended beneficiaries and other key players in a given health intervention could be an incentive for the adoption and uptake of the intervention. This study examined the possible effects of socio-economic incentives to complement communication campaigns to improve the uptake of voluntary medical male circumcision (VMMC) for the prevention of HIV/AIDS in Siaya County of Kenya. Using multi-stage sampling, we purposively selected two sub-counties, Bondo and Rarieda, from where, using the snowball technique, we drew a sample of 370 male residents aged 18 to 49 years, mainly from the fish landing areas of the two sub-counties. We conducted two focus group discussions with men and women residents, besides in-depth interviews with five managers of the programme. Results were drawn from direct and indirect questions touching on socio-economic issues covered in the qualitative and quantitative research instruments and from anecdotal evidence. We found that, besides conventional prevention and treatment programmes, combating HIV/AIDS through VMMC in low-income populations requires reasonable investment in economic assistance to the intended beneficiaries of VMMC and those with the potential to influence their decision. These activities should be integrated in the wider programme implementation spectrum with clear structures that serve as entry points for health message delivery points.
\end{abstract}

Keywords: Siaya, Kenya, healthcare, circumcision, interpersonal communication, livelihood enhancement.

DOI: $10.7176 /$ RHSS/10-12-06

Publication date:June 30th 2020

\section{Introduction}

Behaviour change communication theorists have argued that by assuming that individual beliefs and perceptions hold the key to explaining health behaviours, it is easy for behaviour change communicators to ignore the extraneous constraints that often obtain in the individual's environment, particularly in severely resource-deprived areas (Dutta Bergman, 2009). Access to basic resources, such as food clothing and shelter, can be central to developing an understanding for health communication for many underserved populations found mainly in rural and informal urban dwellings (Aibibula et al, 2017). Studies ( e.g. Narayan et al, 2000) show that a communication-based approach that only focuses on the severity of a health problem and the people's susceptibility to it, and the benefits of or barriers to a prescribed intervention, without addressing the key structural elements have little chances of success. Such chances are even lower when dealing with particularly resourcedeprived parts of the world, where individuals lack the basic necessities of life such as food, clothing, and shelter. Yet many of the structural barriers experienced in low-income populations in health interventions are not overtly related to the specific behaviour being advocated or do not present themselves directly to the scrutiny of the external observer (Mony, Salan et al, 1999; Sarkar et al., 1997). Health decisions might be located in the capability of community members to gain access to some of these basic necessities. In their absence, engaging in "higher order" health behaviors such as having VMMC or safe sex may sound abstract and, thus, prove futile (DuttaBergman, 2009). Therefore, health programme implementers, particularly those charged with communication, need to have more than a fleeting understanding of, and deal appropriately with, the economic situation of the people they are involved with. Studies have attributed the poor performance of communication programmes - both mediated and interpersonal to the tendency to approach health from an individualistic and biomedical perspective (Hodgetts \& Chamberlain, 2006), where according to Campbell and Scott (2011), health-related news stories, advertisements and interactions overwhelmingly frame health as a purely biomedical issue. Such programmes 
place responsibility for change on the unhealthy individual, masking the crucial role played by unequal social environments in shaping health, and in preventing many members of disadvantaged groupings from engaging in health-promoting behaviour.

While studies abound on the nexus between rich or poor people and HIV prevalence, little empirical literature is available on how an individual's income of financial status influences his response to interventions for the prevention of the epidemic. Even less literature is available on how an individual's level of income will be amenable to communication strategies advocating the adoption or a move away from a given health intervention. In examining the trends of HIV/AIDS epidemic in Zimbabwe, Mbirimtengerenji (2007) tried to answer the question as to whether the prevalence of the HIV/AIDS epidemic was an outcome of poverty. The conclusion, in the affirmative, however, does not lend any clue to the question of whether one's low or high income has the potential to hinder or motivate one's participation in health interventions. Two studies done in Tanzania (Shelton et al., 2005) and Kenya (Chin, 2007) found a positive correlation between HIV and poverty. But an investigation by Mishra eat al. (2007) on eight high HIV burden countries - Kenya, Botswana, Malawi, Tanzania, Bukina Faso, Ghana, Lesotho and Uganda (Mishra et al., 2007), yielded contradicting findings, to the effect that adults in the wealthiest quintile had higher HIV prevalence than those in the lower economic rungs. However, none of the above studies attempted to establish how or whether individual or community income status influences their ability to consume health interventions. Such a study would, in turn, inform the decision of health managers on whether to make economic empowerment an integral part of health campaign programmes.

Siaya County which is situated on the western Kenya region along the expansive fresh water Lake Victoria has a largely rural population, with a density of 332 people per square kilometre and poverty level as high as $57.9 \%$ in the rural and 37.9 in the urban areas of the county (Kenya National Bureau of Statistics, 2018). With a gross county product of US\$449, against its neighbouring county of Kisumu, with US\$1,151 or City County of Nairobi, at US\$9,982 (Kenya National Bureau of Statistics, 2019), Siaya County falls among the lowest performers in Kenya. With individual income considered an important factor in the management of diseases in general (Oles et al., 2012; Heymann, 2006), and HIV/AIDS in particular (Shelton et al., 2005; Chin, 2007; Mishra et al., 2007).

\subsection{Objective of the study}

This study sought to establish if the voluntary medical male circumcision implementing partners have incorporated livelihood enhancing projects in the programme's overall implementation matrix in low-income populations of Siaya County and with what effects on the interpersonal communication campaign to soar up the uptake of the intervention.

\section{Methods and materials}

This study employed a mixed-methods approach comprising quantitative and qualitative data collection techniques. We adopted a multi-stage sampling technique, first of research locations and, secondly, of participants. Purposive sampling was used to select the county specific sub-counties. Within the selected sub-counties, proportionate sampling was employed to obtain the desired cases. Five sets of participants constituted the sample frame. We administered and structured on men aged 18 to 50 years $(n=370)$, drawn chiefly from the local fishing community, living within Bondo and Rarieda sub-counties. We then conducted two focus group discussions; one with men living around the fish landing beaches who worked as fishermen, traders, transporters or menial workers $(n=5)$; and, two, among women living along the lake as traders or spouses of residents $(n=4)$. Further, we conducted five key informant interviews, using a semi-structured interview guide, with managerial staff of the two implementing agencies, namely, Centre for Health Solutions, a non-governmental organisation, and the Ministry of Health. We used chain-referral sampling to get the respondents to the questionnaires as well as participants of the focus group discussions. Participants of the key informant interviews were purposively sampled in the basis of their roles in the programme.

A total of 251 male residents of the selected two sub-counties filled and returned the questionnaire, translating to a response rate of $67.47 \%$. Questionnaires returned from the field were coded and keyed into Statistical Package for the Social Sciences (SPSS) computer software for analysis, and data screened using the sort functions. Descriptive statistical analysis was applied to quantitative data. First, we developed a data code sheet and transferred data to IBM SPSS Statistics 22 computer software. Secondly, we undertook data cleaning to identify outliers and remove errors in the data feeding process prior to nalysing. The data were then analysed using descriptive statistics such as frequency distribution, percentages, averages and mean values. For qualitative data, a step-by-step data analysis was done, first transcribing the recordings verbatim then reading through transcriptions and field notes, using the immersion process to better understand the data, and note emerging patterns. We employed the inductive approach to code and organise data into categories and themes. Codes were assigned to the various segments of data to tease out emerging patterns, which were then merged to form various categories. Themes were iteratively compared and assessed by viewing the causal conditions, context, and interactions. Through the induction process, data were interpreted according to the identified themes. 


\subsection{Ethical Approvals}

Prior to visiting the field, we obtained ethical clearance from the Ethics Committee of Masinde Muliro University of Science and Technology, and research permit from the National Commission for Science, Technology and Innovation. Further, we secured the approvals of the following government authorities to collect data in their areas of jurisdiction: County Commissioner; Siaya; County Director of Education, Siaya; Deputy County Commissioner, Maranda; and Director, Centre for Health Solutions. At the same time we ensured that all participants had full disclosure on the study through verbal explanation and the approved consent form. In view of the sensitivity of some socio-cultural and health issues HIV/AIDS and circumcision the participants were assured of strict confidentiality during and after the data collection process.

\section{Results}

The aim of this study was to establish whether activities existed alongside advocacy programme as part of the overall implementation programme for the voluntary medical male circumcision programme in Siaya. The results, derived from both quantitative and qualitative data, are presented and discussed below.

\subsection{Demographic details}

The study engaged the respondents on specific demographic issues, such as age, income or occupation, marital status, and education levels, which have a possible bearing on their economic situation. These factors were seen as capable of negatively or positively influencing the people's response to VMMC as a health intervention aimed at reversing the trends and effect of HIV in Siaya County.

\subsubsection{Age distribution}

The study established that majority $(53.8 \%)$ of the respondents were aged between 28 and 37 years, followed by those aged between 18 and 27 years, representing 28.7\%. Those in the 38- to 47-year bracket accounted for $12.6 \%$. The remaining age brackets accounted for below $10 \%$, as shown in Figure 1 below

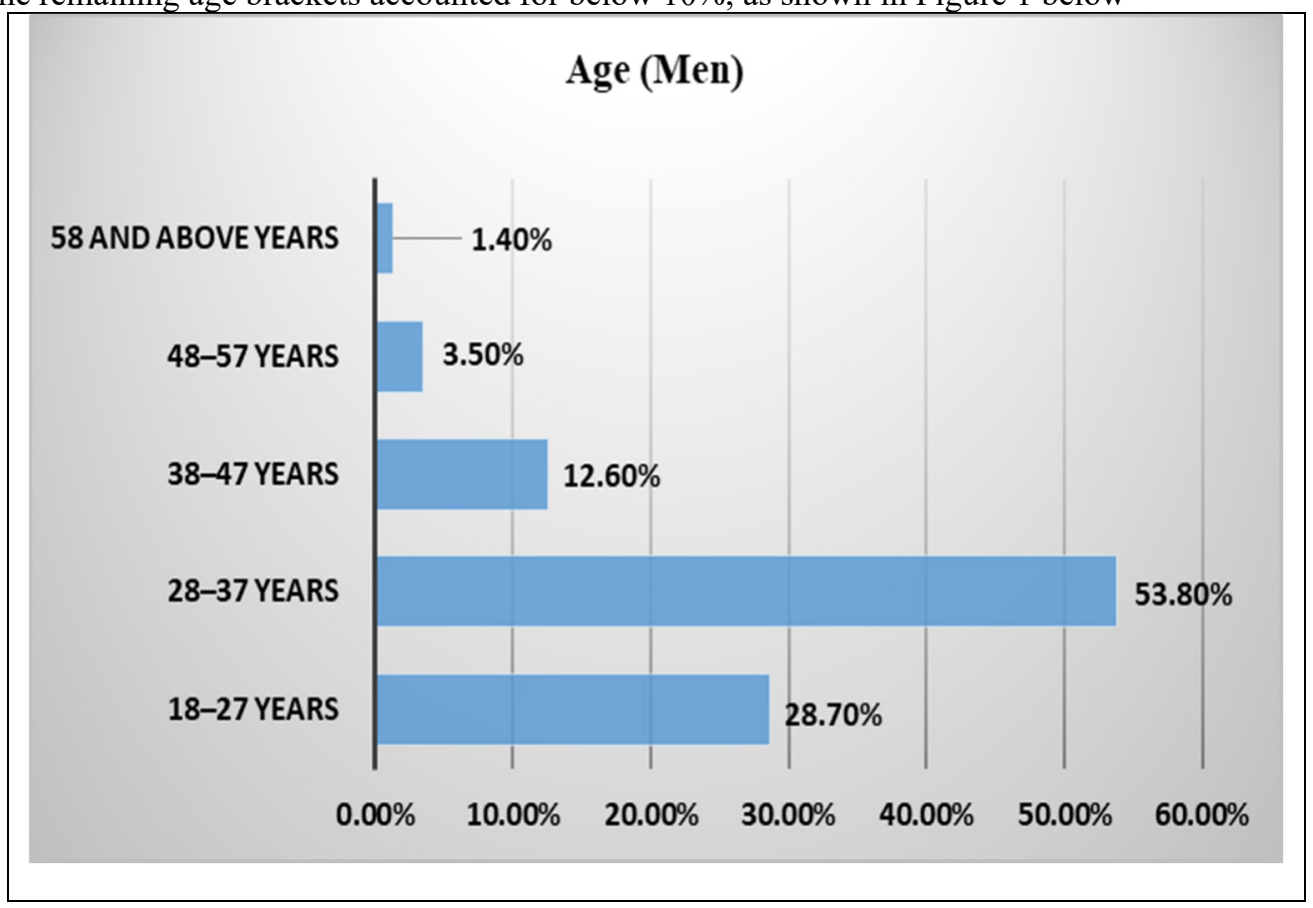

\subsubsection{Marital status}

Figure 1: Men's age distribution

The respondents' marital status indicated that $29.4 \%$ of them were single, while the bulk were married, accounting for 49.0 per cent. Those that were separated represented up to 9.1\%, as shown in Figure 2 below, while those who were divorced or widowed were $4.9 \%$ and $2.1 \%$ respectively. 


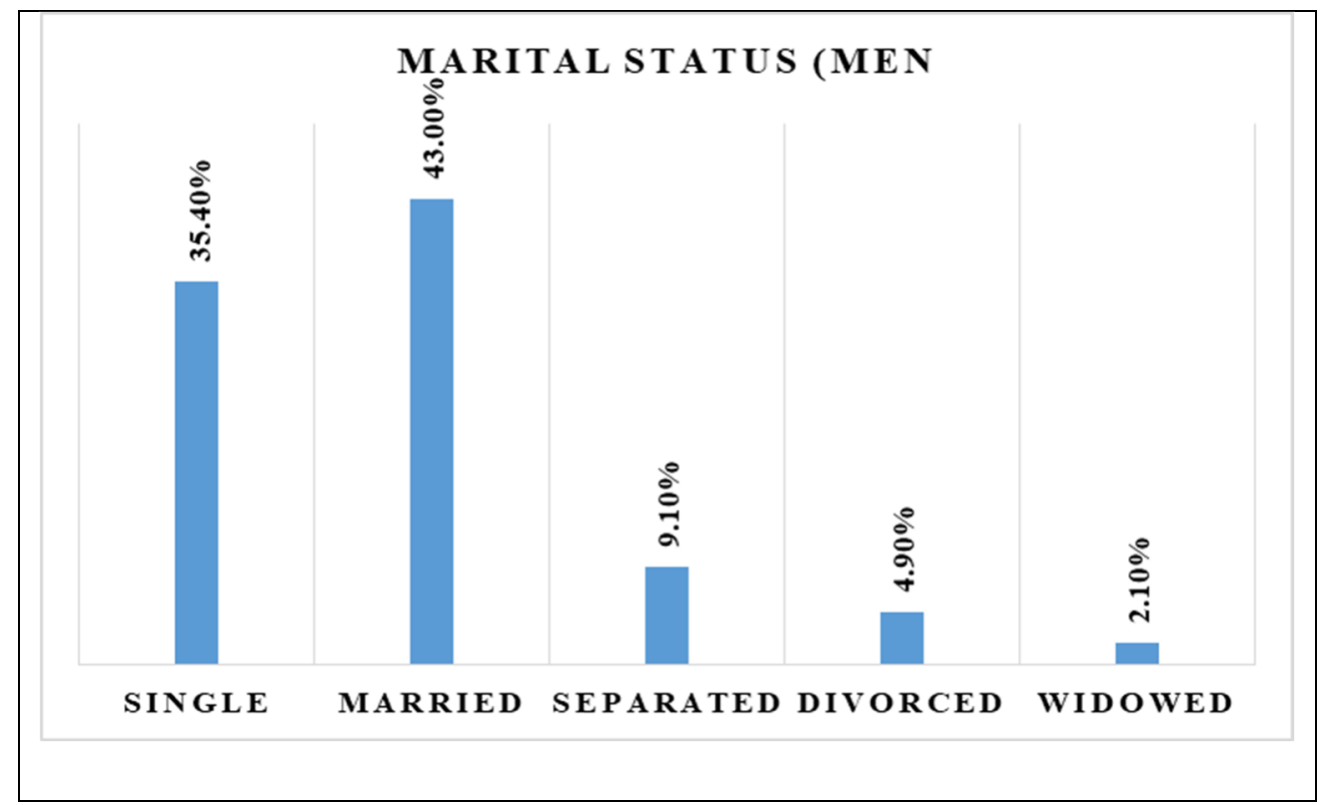

\subsubsection{Economic activity and source of income}

Figure 2: Marital status (men)

The findings show that the majority of the respondents were fishermen, accounting for $64.2 \%$ of all the respondents. The rest of the respondents, represented by a consolidated $35.8 \%$, were engaged in economic activities that support fishing such as transport, sale of fishing gear, fish loading, among others. The findings further show that the respondents were primarily from resource poor background with a consolidated $68.6 \%$ earning US $\$ 100$ and below per month, while only $28.3 \%$ fell in the US $\$ 100$ to US $\$ 150$ bracket, and a paltry $3.1 \%$ above US\$150. Regarding the respondents' spouses, those who earned between US\$50 and US\$100 accounted for $23.1 \%$, while only $10.5 \%$ earned between US\$100 and US\$150, and a small $9.6 \%$ of the spouses earned above US\$150 per month (See Table 1 below). This particular finding shows that the men's spouse, for those who were married, earned relatively less.

Table 1: Demographic details

\begin{tabular}{lll} 
Variable & & $\mathbf{\%}$ \\
\hline & Student & $0.7 \%$ \\
Occupation/ source of & Fisherman & $64.2 \%$ \\
income & Businessman & $16.8 \%$ \\
& Government employee & $6.6 \%$ \\
& Private business employee & $8.8 \%$ \\
& Other & $3.0 \%$ \\
\hline & $<$ US\$15 & 3.7 \\
Man's Average monthly & US\$150 - US\$500 & 23.9 \\
income & US\$501 - US\$100 & 41.0 \\
& US\$101- US\$150 & 28.3 \\
& $>$ US\$150 & 3.1 \\
\hline \multirow{3}{*}{ Wife's average monthly } & Don’t Know & 25.0 \\
income & US\$15 - US\$500 & 34.5 \\
& US\$501 - US\$100 & 23.1 \\
& US\$101 - US\$150 & 10.5 \\
\hline
\end{tabular}

\subsubsection{Clients' level of education}

We established that $50.3 \%$ of the respondents had primary school as their highest level of education, $34.3 \%$ had gone up to secondary school level, $7.7 \%$ were of college level and only $3.5 \%$ had at least a university level of education (See Figure 3 below). 


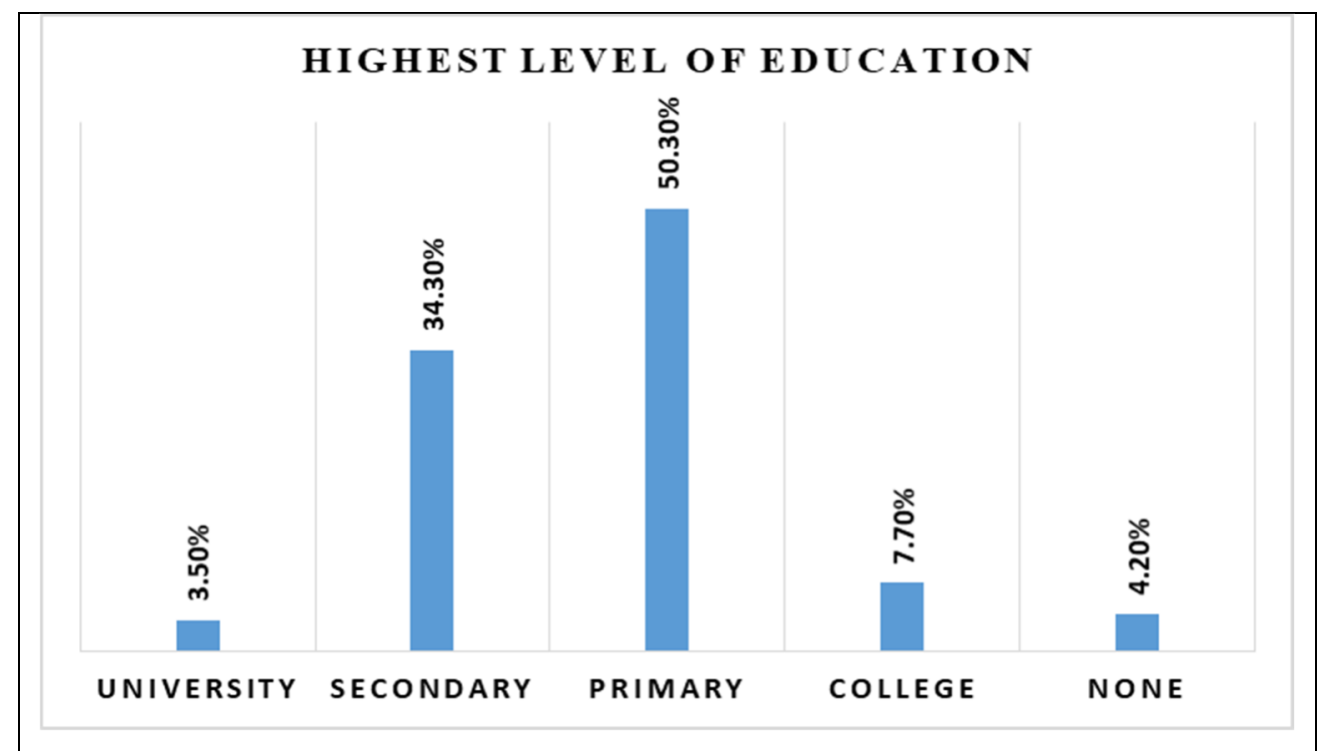

Figure 3: Highest level of education (men)

\subsection{Target client's perceptions on HIV/AIDS and VMMC}

We sought to establish the clients' perceptions about HIV/AIDS as a health problem and VMMC as a health intervention. Such perceptions included vulnerability to HIV, the severity of the consequences of HIV, the benefits of VMMC as an intervention, weighed against factors that discourage its uptake. We found that the most significant barrier to the adoption of VMMC as an intervention against HIV was the fear of loss of income during the healing period after the cut. Up to $83.6 \%$, "To a large extent" and "To a very large extent", that VMMC would condemn them to economic uncertainty during the post-operation healing, something that would check the acceptance of the intervention. Therefore, although the clients had strong perception about their vulnerability to HIV, its severity and the corresponding knowledge that VMMC has a high chance of preventing them from contracting HIV (See Table 2 below), the men' worry of economic incapacitation during the time of recovery appeared to stand in the way of the programme's success.

\section{Table 2: Target clients' perceptions on HIV/AIDS and VMMC}

\begin{tabular}{|c|c|c|c|c|c|}
\hline Reflective Beliefs & & 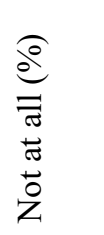 & 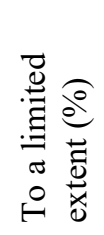 & 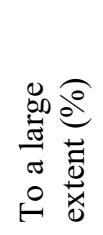 & 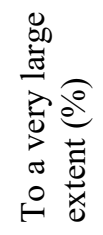 \\
\hline \multirow{3}{*}{ Vulnerability } & I know HIV is prevalent in my area & 2.8 & 4.7 & 51.3 & 42.1 \\
\hline & My lifestyle predisposes me to HIV & 3.1 & 5.7 & 48.5 & 42.6 \\
\hline & My work makes me vulnerable to HIV & 4.7 & 8.8 & 38.4 & 47.1 \\
\hline \multirow{4}{*}{ Severity } & HIV/AIDS is a most devastating disease & 0.8 & 9.0 & 39.5 & 49.8 \\
\hline & The thought of AIDS scares me out of sex & 8.9 & 6.7 & 29.6 & 54.8 \\
\hline & Getting HIV will ruin me and my family & 5.8 & 8.0 & 38.4 & 47.8 \\
\hline & Other will shun me if I'm HIV+ & 2.0 & 8.8 & 42.8 & 46.4 \\
\hline \multirow{4}{*}{ Benefits } & It is hygienic to be circumcised & 3.0 & 10.0 & 48.6 & 38.4 \\
\hline & With VMMC, I can avoid contacting HIV & 10.1 & 16.7 & 48.5 & 24.6 \\
\hline & Being circumcised is now trendy and smart & 10.3 & 20.7 & 46.6 & 19.4 \\
\hline & Sex is more enjoyable if one's circumcised & 18.5 & 29.8 & 35.0 & 16.5 \\
\hline \multirow{5}{*}{ Barriers } & It is embarrassing to be circumcised & 36.8 & 25.6 & 18.6 & 10.0 \\
\hline & Worried about forgoing sex during healing & 12.7 & 16.6 & 29.9 & 40.8 \\
\hline & VMMC operation is painful and risky & 10.3 & 19.6 & 47.2 & 22.9 \\
\hline & Partner may seek sex elsewhere as I heal & 12.9 & 15.9 & 40.6 & 30.6 \\
\hline & My family will starve as I heal after VMMC & 9.6 & 16.8 & 48.8 & 24.8 \\
\hline
\end{tabular}

The focus group interviews further revealed this fear, as participants said that although they were aware that 
the circumcision was assuring them of safety against HIV, their immediate worry was how they would survive economically during the time of recovery.

"Circumcision is good and I know its benefits, but, like me, I am a jua kali (self-employed). If I do it, there is no way I will manage during the six-week recovery period when I cannot do anything for my upkeep. Maybe if these people can help me by way of money or something,"

"I have discussed this even with my wife... and while she supports the cut I have always told her that "unlike you who is just sitting and waiting, I have to look for means and bring food to you and the children... What happens during the whole period when I am recovering and so not doing anything...economically? "You see it's complicated"

"... For me I was circumcised when I was a child and my parents were reasoning for me and I didn't have anything like, say, food to worry about... But you see, someone like him (another participant) unless these people give him some means of income during the six weeks it becomes very difficult for him to abandon his work because he has to put food on the table... He has a responsibility and there are people who depend on him."

Further, when asked what they would choose between an economic project to enhance their livelihoods and VMMC or any other HIV prevention intervention, $69.6 \%$ of the respondents said they prefer economic assistance first and VMMC second, a sign that the people view economic deprivation as their immediate and number one concern.

\subsection{Livelihood enhancing activities undertaken by VMMC implementers}

While we established that the implementing agencies had not initiated any economic activities to run alongside the communication campaigns to boost the uptake of VMMC, both the implementing staff and the clients were in agreement that infusing economic activities into the broader VMMC programme implementation matrix would greatly improve its uptake. Although the operational staff in direct day-to-day contact with the target clients were clear that they were not engaging the target clients in any economic activities, when asked whether they thought inclusion of livelihood boosting projects would bolster their communication campaign thereby enhancing VMMC uptake, $57.5 \%$ of the respondents said economic project would boost the VMMC campaign "to large extent" and $32.4 \%$ said they would "To a very large extent." Only $10.2 \%$ thought such intervention was not significant, as shown in Table 2 above.

The focus group discussion participants were equally clear that helping them economically would make the programme succeed through their engagement in the promotion campaigns. One woman participant posed:

"Don't these people have a way in which they can help me to help my man...? Like after he has been cut, they boost this small business of mine so that I can get a way of feeding him well during the time he is recovering... That way I will be able to take care of him and the family for the period. If they can do that and other women see this they will be encouraged to convince their men to also take the cut."

Another participant suggested: "there are number of youth groups or women groups which the people can take advantage of to propagate the male circumcision message... provided they are ready to assist them financially so that they can also meet their needs."

The service providers reported that during their interpersonal interactions to popularise the intervention among the clients, the issue of economic empowerment for the latter often came up. Up to 83.5 percent of the respondents reported that the matter came up "Very often" and "Often," with only 13.7 saying they rarely encountered such issues during the campaigns. However, perhaps due to their interactants' inability to act on a policy issue such as starting economic programme, the target clients expressed their view that the implementing agencies were not interested in their socio-economic wellbeing, with over 80 percent saying the service providers showed insignificant interest in addressing their economic concern. The managers interviewed as key informants also said they were aware of the issue of economic assistance as a way of boosting the VMMC uptake; but, thus far, there was nothing on the ground.

"Indeed, that is a big issue; but I always tell them that this programme is for their own benefit. I even remind

them that VMMC is voluntary, which is why the letter ' $V$ ' is there. So I try to implore them not to expect any financial gains by agreeing to be circumcised. I try to counsel them to plan their finances well before go for the operation so that they can still take care of their families as they heal."

Yet another "The lack of economic assistance is there...And that is the biggest challenge. You see any person who is 25 and above, their focus is the family and before they make any decision they must think about how that decision will affect them economically...It's something that we must think about very seriously."

\subsection{Discussion}

This study set out to establish whether there are any livelihood enhancing projects being undertaken alongside the communication strategies in the implementation of voluntary medical male circumcision in Siaya county of Kenya. In addition to specific questions on whether such projects existed and their effects, the study explored a raft of 
demographic factors which could have a bearing on the economic status of the intervention's target clients. These factors included client's age, source and level of income and level of education. We further asked direct questions relating the implementation of livelihood enhancing activities and their bearing on the overall VMMC programme outcome

\subsection{Age as a factor and marital status}

The study puts the dominant age of respondents, who were mainly fishermen, at between 18 and 47 years. This age bracket accounts for 95.1 percent with the highest concentration being age $28-27$ which represents 53.8 percent. This finding is congruent with an earlier study (Omwenga, Abila \& Lwenya, 2006) on fishing in Lake Victoria which also established the average fishers at 21 to 45 years with a mode of 28 years. In the focus group discussion it was revealed that one key consideration in making decision to go for VMMC was the level of responsibility. The participants demonstrated that one was more likely to go for the cut when they were assured that they would not run into financial difficulties during the healing period. There was a negative correlation between the ages of those who answered in the affirmative the question: Would you go for VMMC if the initiative is not accompanied by an economic reward? The target clients for the programme range from age zero to 60, according to the national VMMC guidelines (Ministry of Health, 2009). This diverse clientele age brackets means that the implementers of the programme must have an equally diverse communication strategies targeting the different age sets. The men's marital status also appears to have a bearing. There was a positive correlation between marital status and demand for economic assistance as a condition for accepting the VMMC.

\subsection{Clients' Level of Education}

The bulk of the people have primary education as their highest level of education. Only $11.2 \%$ had college and university education with the rest falling under secondary, primary levels of education or none. The finding on the level of education among the predominantly fishing population is in consonance with the study by Luomba et al (2003) in Tanzania, and Evens and others in Kenya (2014), both of which show that the dominant level of education among fishers in the Lake Victoria region is primary. Being a key determinant of employment and, hence, income or poverty levels (Oyugi and Alwanga (2003), education was a major factor in this study. A study on the state of poverty in Kenya has shown that poverty rates decrease with increase in the education level of household head with the headcount poverty rates being "highest among households headed by individuals with no formal education and lowest in households where the headship had acquired a tertiary level of education or higher" (Kenya National Bureau of Statistics, 2018: 11).

Moreover, research has shown that people with low education, and those with low incomes receive low quality healthcare (Institute for Research on Poverty, 2016). With spiraling unemployment in Kenya, it is becoming increasingly difficult for primary and secondary school leavers to find a reasonably well paying job. Moreover, as Luomba and et al (2013: 98) aver, the level of education is important in the study of economic status as education "enables one to adapt to new technologies that leads to poverty reduction, economic growth and sustainable utilisation of resources..." Fishing is largely considered a low paying job with most fishers living from hand to mouth (Abila, et al, 2006).

Moreover studies have shown that the fisher community is averse to the saving culture, with most men living from hand to mouth ensconced in the belief that with fish in the water, there will always be money tomorrow (Abila et al., 2006; Okello et al., 2015). Thus, the poor saving culture among the fishing communities exacerbates their economic situation when the government imposes periodical bans on fishing to allow different fish species to breed and grow. As Kundu et al, (2010) say in their study on the state of fisheries on Kenya's Lake Naivasha, although the bans are necessary to allow specific fish species to breed and grow, they have devastating consequences on the livelihoods in the fishing communities, including causing family breakups and evictions from rented dwellings. Opinions abound (e.g. Narayan et al. 2000; Dutta Bergman, 2009; Aibibula et al, 2017) that people with such socio-economic burdens find it difficult to adhere to seemingly high-end health prescriptions.

\subsection{Income levels}

The population involved in this study was generally resource poor people with the bulk $(67.6 \%)$ of them earning between US\$ 15 and 100 per month, putting the majority of them well within the World Bank established poverty bracket of US\$1 a day. The study agrees with one done among fishers in Rachuonyo area, also along Lake Victoria, which found that the concern about the financial burden of VMMC was especially common among men who earned a daily wage such as fishermen and those in the transport sector. Moreover, this study's finding depicts gender disparity in favour of men, further agreeing with an earlier study (Kiriti \& Tisdell, 2003), which found that in Kenya women had lower income than men, and yet another by the UNDP (2000), which reported that of the over 1.3 billion people in absolute poverty globally, the majority were women, mainly found in rural areas and informal peri-urban settlements. The loci of this study, the fish landing beaches, and their surroundings, with fisher folk being the key targets. As Dutta-Bergman (2009) argues, when people have immediate issues of basic needs 
to worry of, it becomes difficult to give their undivided attention to issues like VMMC, which to them are "highend" health issues that they see as far in the horizon.

Mbirimtengerenji (2007) further argues that even if the people who are economically deprived understand what they are being urged to do, it is rarely the case that they have either the incentive or the resources to adopt the recommended behaviours. Although not targeted for the circumcision, women have particularly important role to play in the implementation of VMMC, falling in the category that Fishbein \& Ajzen (2010) refer to as "significant others." Firstly, as wives, women are relied on to provide economic and psycho-social support to their husbands in making the decision to go for the cut. Secondly, as mothers, they hold a significant sway in nursing their sons, who are also targeted for the VMMC. However, as a wife a woman's power to negotiate on matters sexual seems to be directly proportional to their economic wherewithal (Moret, 2014). Furthermore, as the women participants of the focus group discussions revealed, key in their list of worries is how they will be able to take care of their families, including the husbands, who will be economically incapacitated during the time of healing.

\subsection{Clients' perceptions on HIV/AIDS and VMMC}

Guided by the belief that health events are positively or negatively evaluated on the basis of their expected good or bad outcome (Corcoran, 2007; Becker, Haefner \& Maiman, 1977), we sought to establish the clients' perceptions about HIV/AIDS as a health problem and VMMC as a health intervention. Such perceptions included vulnerability to HIV, the severity of HIV, the benefits of VMMC as an intervention, weighed against factors that discourage its uptake (barriers). While the findings show clients' great awareness of the their susceptibility to HIV and severity of the disease as well as the benefits of VMMC, they equally reveal that over 80 percent of the target beneficiaries surveyed believed that VMMC would condemn them to economic uncertainty during the postoperation healing, a factor that makes them hesitant to accept the cut.

Thus, although the men are clearly aware that they are susceptible to HIV and that the disease is severe, with some FGD participants equating HIV to death sentence, the fact that a majority of the men would not accept VMMC on account of economic considerations, should be a source of worry for the programme's implementers. This finding supports an earlier study (Evens et al, 2014), which found that men between the ages of 25 and 35 years expressed particular concern about the financial implications of VMMC. It is noteworthy that the majority of the respondents for this particular study fell within the same age bracket of $28-37$ years) as identified in the study by Evens et al (2014) as most worried about the financial effects of VMMC.

Furthermore, the study has established a nexus between poverty and spread of HIV. Part of the factors that the participants blamed for the spread of HIV is the use of money by fishers to buy sex. The men with their poor money saving culture (Omwenga, et al, 2006), use their earnings to lure women into sex. Such women come in two main categories namely commercial sex workers plying their trade along the beaches and women fish traders who give in to fishers' sexual advances in order to get fish from them under the infamous sex for fish model that has taken root in most of fishing communities of Lake Victoria (Fiorella et al. 2015). We further established a third category consisting of women who live in the villages surrounding the fish landing sites.

With rampant poverty in Kenya's rural setting (Kenya National Bureau of Statistics, 2018), young women living on the lakeshores fall easy prey to sex overtures by the fishermen who, by the rural standards rank among the financially endowed. Incidentally, buying of sex is not confined to men alone, as we learnt in the focus group discussions. With what one participant described as "a strange appetite for young blood," women living and working along the beaches, mainly as fish traders or gear owners, also engage in sex with young men whom they give money or engage in casual employment. The key informant interviewees drawn from among them programmes managers and supervisors also identified the commercial sex a significant menace they were grappling with.

Thus, with the rampant incidences of commercial sex activities, low income and poverty, the inclusion of well-targeted economic projects would be an obvious consideration. However, we found that there were no livelihood enhancing economic projects run alongside the health communication campaign. The interviewees said that no specific programmes were in place to address the economic needs of their target clients. All the FGD, participants, on their part, said that economic activities addressing their socio-economic needs would go a long way in enhancing the uptake of VMMC, especially if such economic programmes could be there to cushion them and their dependants from suffering during the post-circumcision healing period. The service providers were also convinced that the inclusion of livelihood boosting projects would bolster their communication campaign thereby enhancing VMMC uptake. The findings are in consonance with the findings by Okello et al. (2015), who in their study on challenges among the fishing community in Homalime and Kenya Bay also on the Kenyan side of Lake Victoria found that women were engaging in prostitution or sex for fish not because they liked it but as a result of harsh economic circumstances.

These findings on the role of socio-economic support for target clients to enhance the uptake of health interventions support several other studies (Narayan, Chambers et al, 2000; Narayan, Patel et al, 2000; The Synergy Project, 2002), which have shown that an interpersonal communication-based approach that only focuses 
on benefits of a given health intervention without addressing the key structural elements as barriers to the success of the intervention particularly in resource-deprived settings, where individuals lack the basic necessities of life such as food, clothing, and shelter, have little chances of success. This standpoint is supported by several studies (Dutta-Bergman, 2009; UN, 2018) that have advocated that theoretical approaches to health campaigns ought to locate mitigation of poverty and lack of basic resources at the center of human behaviour and communicative choices. In his critique of the U.S. President's Emergency Plan for AIDS Relief (PEPFAR), Evertz (2010) argues that the project's weakest point is the failure to link its activities to the structural realities on the ground. For instance, the programme has overlooked the fact that some people such as commercial sex workers engage in the dangerous behaviours because of their economic difficulties. He quotes the statement by an Ethiopian commercial sex worker thus: "Anybody can abstain and be faithful if they have shelter and food."

\section{Conclusion and recommendation}

This study set out to answer the twin questions of if there were livelihood enhancing projects being implemented as an integral part of the campaign to boost the acceptance and adoption of voluntary medical male circumcision in Siaya county of Kenya, and with what effects. Consequently it has established two facts: that there are no economic activities that the VMMC programme implementers are running in the county, and that this has had negative effect on the success of the programme and significantly slowed the rate of adoption, particularly in the resource-poor populations of the county. Although heralded as veritable entry points for disseminating health information among low income populations, the programme's two implementing partners, the Ministry of Health and Centre for Health Solutions have no plan to infuse any economic interventions in the programme. Nevertheless, this study has proved that the inclusion of economic activities among the VMMC target clients holds the potential to the success of the programme, particularly if the upper rungs of the target clients - comprising those of 18 years and above. Siaya County ranks among the low-income counties in Kenya with more than half the population living below the poverty line. In the resource-deprived parts of the county, the residents tend to focus their attention on their livelihood and may not give much thought to health interventions, especially when they do not address their immediate basic needs like food, clothing and shelter. The infusion of livelihood enhancing activities would go a long way in boosting the outcome of the VMMC programme. This study therefore proposes the integration of economic activities in the VMMC implementation programme matrix to run alongside the communication programme. The twin problem of low income and the potential of VMMC to render circumcised men economically inactive during the healing period make a strong case for inclusion of economic incentives for those target in the programme.

\section{References}

Abila, R.O. (2003) Fish trade and food security: are they reconcilable in Lake Victoria? In: FAO, Report of the Expert Consultation on International Fish Trade and Food Security, Casablanca, Morocco, 27-30 January, 2003. FAO Fisheries Report No. 708. Food and Agricultural Organization, Rome, pp. 128-153

Aibibula, W. et al (2017) Impact of Food Insecurity on Depressive Symptoms among HIV-HCV Co-infected People. AIDS and Behavior volume 21, pages3464-3472(2017)

https://link.springer.com/article/10.1007/s10461-017-1942-z?shared-article-renderer

Becker, M., Haefner, D. \& Maiman, L. (1977) The health belief model in the prediction of dietary compliance: a field experiment, Journal of Health and Social Behaviour, 18, 348-66.

Corcoran, Nova (2007). Theories and models in communicating health messages In Nova Corcoran (Ed.) Communicating Health: Strategies for Health Promotion, Sage Publications.

Campbell, Catherine \& Scott, Kerry (2011) Mediated health campaigns: from information to social change. In: Hook, Derek, Franks, Bradley and Bauer, Martin W., (eds.) Social Psychology of Communication. Palgrave Macmillan, Basingstoke, UK, pp. 266-284. ISBN 9780230247369

County Government of Siaya (2014). Siaya County HIV \& AIDS Strategic Plan ((2015/16 - 2018/2019)

Dutta-Bergman, M.J. (2004). Primary sources of health information: Comparisons in the domain of health attitudes, health cognitions, and health behaviors. Health Communication, 16(3), 273-88.

Evens E, Lanham M, Hart C, Loolpapit M, Oguma I. et al. (2014) Identifying and Addressing Barriers to Uptake of Voluntary Medical Male Circumcision in Nyanza, Kenya among Men 18-35: A Qualitative Study. PLoS ONE 9(6): e98221. doi:10.1371/journal.pone.0098221

Evertz, S. H. (2010) How Ideology Trumped Science: Why PEPFAR has Failed to Meet its Potential, Centre for American Progress

Fiorella, K., Camlin, C., Salmen, C., Omondi, R. et al. (2015) Transactional Fish-for-Sex Relationships amid Declining Fish Access in Kenya

Fishbein, M. \& Cappella, J. N. (2006) The Role of Theory in Developing Effective Health Communications. Journal of Communication. DOI: 10.1111/j.1460-2466.2006.00280.x

Hodgetts, D. and Chamberlain, K. (2006) Developing a Critical Media Research Agenda for Health Psychology. 
Journal of Health Psychology 11: 317-327.

Heymann, D. (2006) Effects of social, environmental and economic factors on current and future patterns of infectious diseases. ScriptaVaria 106, Vatican City www.pas.va/content/dam/accademia/pdf/sv106/sv106heymann.pdf

Kenya National Bureau of Statistics (March 2018) Basic Report on Well-Being in Kenya. Based on the 2015/16 Kenya Integrated Household Budget Survey (KIHBS

Kiriti, T. \& Tisdell, C. (2003) Gender Inequality, Poverty and Human Development in Kenya: Main Indicators, Trends and Limitations. AgEcon Search. 10.22004/ag.econ.105587 ISSN: 14428563 (Other)

Kundu, R., Aura, C., Muchiri, M., Njiru, J. \& Ojuok, J. (2010) Difficulties of fishing at Lake Naivasha, Kenya: Is community participation in management the solution? Lakes \& Reservoirs: Research and Management 2010 15: 15-23. Doi: 10.1111/j.1440-1770.2010.00419.x

Luomba, J., Salehe, M. \& Mlahagwa (2013) An assessment of the socio-economic status of fishers' communities in Lake Victoria, Tanzania in relation to poverty. International Journal of Research in Fisheries and Aquaculture. http://www.urpjournals.com

Lwenya C. and Abila R. (n.d.), Co-Management in the Lake Victoria Fishery, Realities, Constraints and Opportunities in Kenya. Kenya Marine and Fisheries Research Institution. Kisumu, Kenya.

Male Circumcision Consortium (2014) Interventions to Address Barriers to Voluntary Medical Male Circumcision

Mbirimtengerenji, N. D. (2007) Is HIV/AIDS Epidemic Outcome of Poverty in Sub-Saharan Africa? Croat Medical Journal. 48:605-17

Mony, T., Salan, E., Youthy, E., Piseth, E. S., \& Brown, E. (1999) Crossing borders crossing realities: The vulnerability of Vietnamese sex workers in Cambodia.Kuala Lumpur, Malaysia: CARAM Cambodia

Moret, W. (2014) Economic Strengthening for Female Sex Workers: A Review of the Literature May 2014 ASPIRES, FHI 360

Narayan, D., Chambers, R., Shah, M. K., \& Petesch, P. (2000) Voices of the Poor: Crying out for Change. New York: Oxford University Press.

Narayan, D., Patel, R., Schafft, K., Rademacher, A., \& Koch-Schulte, S. (2000). Voices of the Poor: Can Anyone Hear Us? New York: Oxford University Press.

Okello, E., Osamba, J. \& Parsitau, D. (2015) Challenges Facing the Fishing Industry in Homalime and Kendu Bay Zones of Lake Victoria in Homabay County, Kenya. Historical Research Letter. Vol. 19, 2015. ISSN 22243178 (Paper) ISSN 2225-0964

Oles, K., Gudowska-Nowak. E. \& Kleczkowski A. (2012) Understanding Disease Control: Influence of Epidemiological and Economic Factors. PLoS ONE 7(5):e36026. doi:10.1371/journal.pone.0036026

Omwenga R.N., Abila R. and Lwenya C. (2006) Fishing and Poverty Levels Around Lake Victoria (Kenya), Kenya Marine and Research Institution, Kisumu (Kenya).

Oyugi A, Obiero N, Awanga, J. (2003) Poverty reduction' a challenge for the Lake Victoria Basin [Kenya].

Sarkar, S., Durnadincommercial sex workers in a brothel of Bangladesh on knowledge, intent, trial, and practice for use of condom. Paper presented at the Sixth Annual Scientific Conference, Dhaka, Bangladesh.

Wamoyi, J., Fenwich, A., Urassal, M., Zaba, B. \& Stone, W. (2011) Parent-child communication about sexual and reproductive health in rural Tanzania: Implications for young people's sexual health interventions. BMC Pub Med 11: 106

\section{Authors' bio-data}

Osir Otteng is the corporate communications manager at South Eastern Kenya University, and teaches communication and journalism at university level. His research articles on health communication, organisational communication, media and democratic governance have been published in peer-reviewed journals. He is finalising his PhD study in health communication at Masinde Muliro University of Science and Technology, Kenya.

Prof. Michael Kiptoo is the Chief Executive Officer of Kenya Medical Training College and Dean School of Nursing Science and Public Health at South Eastern Kenya University. A specialist of immunology and virology, Prof. Kiptoo, has widely researched and published two books in immunology and over 40 articles in peer-reviewed journals in immunology, virology and public health.

Dr. Peres Wenje is the dean, School of Arts and Social Sciences, Masinde Muliro University of Science and Technology. His teaching and research interest are in the area of development communication, specialising in health communication. He has researched and published extensively on information dissemination and education, behavior change, social marketing and media advocacy, focusing on health management.

\section{Acknowledgements}

We thank Ms Grietje Wille Legacy under the ASALI (A Sustainable Approach to Livelihood Improvements), a joint research project of Vrijè Universiteit Amsterdam, the Netherlands, and South Eastern Kenya University, Kenya, for funding this study up to its publication. We also thank all the respondents from the Ministry of Health, 
Siaya and the Centre for Health Solutions, who willingly contributed to this study, as well as government authorities, who granted us permission to conduct the research in their areas of jurisdiction. We are further grateful to Mr. John Maira, our research assistant, who diligently worked with us in data collection, and Ms. Jeanne Mwangangi, for meticulously proofreading the final draft of the manuscript. 